\title{
Improving the diet of employees at blue-collar worksites: results from the 'Food at Work' intervention study
}

\author{
Anne D Lassen ${ }^{1, *}$, Anne V Thorsen ${ }^{1}$, Helle M Sommer ${ }^{2}$, Sisse Fagt ${ }^{1}$, Ellen Trolle ${ }^{1}$, \\ Anja Biltoft-Jensen ${ }^{1}$ and Inge Tetens ${ }^{1}$ \\ 'Department of Nutrition, National Food Institute, Technical University of Denmark, Mørkhøj Bygade 19, \\ DK-2860 Søborg, Denmark: ${ }^{2}$ Department of Microbiology and Risk Assessment, National Food Institute, \\ Technical University of Denmark, Søborg, Denmark
}

Submitted 7 September 2009: Accepted 28 0ctober 2010: First published online 4 January 2011

\begin{abstract}
Objective: To examine the impact of a 6-month participatory and empowermentbased intervention study on employees' dietary habits and on changes in the canteen nutrition environment.

Design: Worksites were stratified by company type and by the presence or absence of an in-house canteen, and randomly allocated to either an intervention group (five worksites) or a minimum intervention control group (three worksites). The study was carried out in partnership with a trade union and guided by an ecological framework targeting both individual and environment levels. Outcome measures included: (i) changes in employees' dietary habits derived from $4 \mathrm{~d}$ pre-coded food diaries of a group of employees at the worksites (paired-data structure); and (ii) the canteen nutrition environment as identified by aggregating chemical nutritional analysis of individual canteen lunches (different participants at baseline and at endpoint).

Setting: Eight blue-collar worksites (five of these with canteens).

Subjects: Employees.

Results: In the intervention group ( $n$ 102), several significant positive nutritional effects were observed among employees, including a median daily decrease in intake of fat $(-2 \cdot 2 \% \mathrm{E}, P=0 \cdot 002)$ and cake and sweets $(-18 \mathrm{~g} / 10 \mathrm{MJ}, P=0 \cdot 002)$ and a median increase in intake of dietary fibre $(3 \mathrm{~g} / 10 \mathrm{MJ}, P<0 \cdot 001)$ and fruit $(55 \mathrm{~g} / \mathrm{d}, P=0.007$ and $74 \mathrm{~g} / 10 \mathrm{MJ}, P=0.009)$. With regard to the canteen nutrition environment, a significant reduction in the percentage of energy obtained from fat was found in the intervention group (median difference $11 \% \mathrm{E}, P<0 \cdot 001, n 144$ ). Conclusions: The present study shows that moderate positive changes in dietary patterns can be achieved among employees in blue-collar worksites.
\end{abstract}

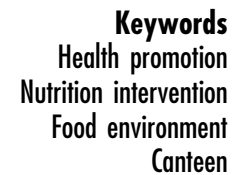

Keywords utrition intervention Canteen
Socio-economic indicators such as occupational status and education level have been associated with weight status and gain ${ }^{(1,2)}$. Population-based health promotion programmes to prevent and combat obesity should therefore be developed and evaluated with special focus on narrowing the social gradient ${ }^{(3-5)}$.

Worksites are seen as important arenas in which behavioural patterns, including healthy eating, can be promoted $^{(6-9)}$. Worksites provide a natural social context, most employees eat one or more meals during their workday, and could potentially reach a large number of people, including many who would otherwise be unlikely to engage in preventive health behaviour ${ }^{(7,10)}$. However, few studies have been focusing on healthy eating behaviour of workers in blue-collar worksites, and many worksite health promotion programmes have been using traditional methods (i.e. individual counselling, education, group sessions) to increase knowledge and skills to stimulate healthy behaviour ${ }^{(11)}$. In recent years, in line with the ecological and socio-ecological models, a shift has been seen towards moving nutrition from a primarily individual issue to an environmental concern $^{(12,13)}$. It is assumed that environmental strategies should at least be incorporated in traditional worksite health promotion programmes to achieve greater behavioural changes and reach a wider audience ${ }^{(11,14)}$.

The present 'Food at Work' study was conducted in eight blue-collar worksites in partnership with the General Workers' Union in Denmark, mainly organizing unskilled workers. The aim of the study was to investigate opportunities and impacts of promoting healthy eating in bluecollar worksites using a participatory and empowerment 
research approach. The process evaluation of the study was described in a previous paper ${ }^{(15)}$, including the number and kind of nutrition-related activities the employees participated in, and the involvement of key actors, including union representatives. The present study evaluates the impact of the intervention on (i) employees' dietary intake derived from $4 \mathrm{~d}$ pre-coded food diaries; and (ii) changes in the canteen nutrition environment as identified by chemical analysis of employees' canteen lunches.

\section{Method}

\section{Worksite recmitment and study design}

Eight worksites, both with and without in-house canteens, recruited by the General Workers' Union were included in the study. The worksites were all previously nominated as 'worksites of the year' by the union itself and hence assumed to have a good employee-employer relationship.

The first task was to establish project groups at each worksite. The project groups consisted of at least one union or workers' safety representative, one manager representative, the canteen manager (if in-house canteen) and other relevant participants. Initially, a $2 \mathrm{~h}$ start-up meeting was held with the project group at each site in order to describe the project programme, discuss the principles of collaboration, project goals and tasks and open the discussion on the constraints and opportunities in relation to health promotion at worksites.

Baseline data collection was carried out and worksites were stratified by company type (e.g. production unit, transport industry and park facility) and by the presence or absence of an in-house canteen. Subsequently, the stratified worksites were randomly assigned to either an intervention group (five worksites) or a minimum intervention control group (three worksites). The intervention group included two worksites without canteens consisting of a zoological garden and a production unit, and three worksites with canteens consisting of a transport company and two production units. At one of the production units, two canteens participated in the study. The minimum intervention control group included the following worksites: a zoological garden with a canteen, a production unit with a canteen and a transport company without a canteen. After randomization of worksites, a $1 \mathrm{~d}$ 'kick-off' seminar was held for all members of the eight worksites' project groups. The intervention period lasted from March to September (6 months), and was performed in accordance with the ethical standards of the Helsinki Declaration of 1975, as revised in 2008.

All worksites were offered a monthly news magazine highlighting achievements at the worksites during the intervention period. In addition, the intervention worksites were offered two kinds of handout materials (nutrition quizzes and dinner mats). Apart from that, the project groups at each worksite were responsible for initiating and completing nutrition-related activities. Intervention worksites were, however, repeatedly encouraged to initiate nutrition-related activities addressing both individual and environment levels in accordance with the ecological framework. Separate meetings were arranged with canteen staff in order to engage all staff, setting goals for the work and tailoring initiatives at the canteen to the specific worksite. Moreover, the canteen staff were offered network and education opportunities. Table 1 provides a schematic overview of the initiatives implemented at the intervention and minimum intervention control worksites. The worksites

Table 1 A schematic overview of initiatives implemented in the intervention and minimum intervention control worksites

\begin{tabular}{|c|c|c|c|c|c|c|c|c|}
\hline & \multicolumn{5}{|c|}{$\begin{array}{l}\text { Intervention } \\
\text { group }\end{array}$} & \multicolumn{3}{|c|}{$\begin{array}{l}\text { Minimum intervention } \\
\text { control group }\end{array}$} \\
\hline & $\begin{array}{c}\text { Production } \\
\text { unit }^{*} \\
(n 400)\end{array}$ & $\begin{array}{c}\text { Transport } \\
\text { company } \\
(n 550)\end{array}$ & $\begin{array}{c}\text { Production } \\
\text { unit }^{*} \\
(n 750)\end{array}$ & $\begin{array}{c}\text { Production } \\
\text { unit } \\
(n 60)\end{array}$ & $\begin{array}{l}\text { Zoo } \\
(n 45)\end{array}$ & $\begin{array}{c}\text { Production } \\
\text { unit* }^{*} \\
(n 500)\end{array}$ & $\begin{array}{l}\text { Zoo* } \\
(n \text { 150) }\end{array}$ & $\begin{array}{c}\text { Transport } \\
\text { company } \\
(n 75)\end{array}$ \\
\hline \multicolumn{9}{|l|}{ Changes in the physical food environment } \\
\hline Free fruit programme & & $x$ & & & $x$ & & $(x)$ & $(\mathrm{x})$ \\
\hline Healthy canteen choices & $(\mathrm{x})$ & $x$ & $x$ & & & & & \\
\hline Weekly food deliveries & & & & & $x$ & & & \\
\hline Healthy lunchtime clubs & & & & $(x)$ & $(x)$ & & & \\
\hline Free cold water & & & & $x$ & & & & \\
\hline Curtail soda and candy sales & & $\mathrm{x}$ & $\mathrm{x}$ & $\mathrm{x}$ & & & & \\
\hline \multicolumn{9}{|l|}{ Information and dialogue-based initiatives } \\
\hline Kick-off event & $x$ & $x$ & $x$ & & & & & \\
\hline Food workshop/taste demonstrations & & & & & $\mathrm{x}$ & & & \\
\hline $\begin{array}{l}\text { Informational material (e.g. nutrition quizzes, } \\
\text { dinner mats, computer-based activities, leaflets) }\end{array}$ & $x$ & $x$ & $x$ & $x$ & $x$ & & & \\
\hline Monthly news magazine & $x$ & $x$ & $\mathrm{x}$ & $x$ & $\mathrm{x}$ & $x$ & $\mathrm{x}$ & $(\mathrm{x})$ \\
\hline \multicolumn{9}{|l|}{ Organizational changes } \\
\hline Health policy & & & $\mathrm{x}$ & & $\mathrm{x}$ & & & \\
\hline
\end{tabular}

$n$ denotes number of employees at the worksites; $\mathrm{x}$, initiative available for all employees; (x), initiative available for a selected group of employees. *With in-house canteen. 
in the minimum intervention control group were asked to preferably postpone initiating nutrition-related activities until after the endpoint measurements. Nevertheless, two worksites in the minimum intervention control group already started fruit schemes for certain groups of employees during the intervention period. More information on project implementation and activities is presented elsewhere $^{(15)}$.

\section{Employee dietary survey}

The union representatives were asked to select at random twenty-five to thirty employees from each worksite to participate in the survey at baseline and endpoint. Pregnant women and individuals not expecting to be present at the particular workplace at endpoint were excluded from the study. At one of the worksites in the minimum intervention control group (i.e. a transport company), the number of individuals selected was lower than intended because of difficulties in reaching employees at the worksite. In order to avoid weakening of the study design because of less people participating, more employees at the other worksite from the minimum intervention control group were recruited to participate in the survey. As employees are the unit of analysis, selection bias is automatically averaged out.

The dietary recording method used was a combination of a personal interview (face to face) and self-administered food diaries. The methodology of the dietary record was identical to the record used in the Danish National Dietary Survey ${ }^{(16)}$. The registration period was, however, shortened from 7 to $4 \mathrm{~d}$ in order to reduce the burden on participants and thus possibly improve compliance. One weekend day was included to evaluate the effect of the intervention on total dietary intake. Trained interviewers interviewed the participants at baseline and at endpoint with regard to their background, habits and attitudes towards food eaten at the worksite, as well as regarding behaviour, knowledge and attitude towards healthy food. They were also asked questions relating to their dietary record, dietary motivations and finally general health. The interviewers also instructed the participants on how to fill in the food diaries. The food diaries consisted of pre-coded answer options for the most commonly eaten foods and dishes in the Danish diet, organized chronologically according to the typical daily meal pattern. For food items not included in the pre-coded food diaries, the participants were asked to add type of food and amount eaten in open-answer categories. The portion sizes were given in pre-defined household measures (cups, spoons, slices, etc.) or estimated from photographs on different portion sizes. The union representatives were asked to collect the food diaries when completed.

In order to encourage participation in the survey, employees were given individual feedback on results from both baseline and endpoint food diary registrations. In addition, small gifts (a lunch box and/or a backpack with the project logo on) were given to all employees who completed both registrations. Furthermore, the main results from the survey relating to the worksite were offered to the project groups at each worksite.

Across the eight worksites, 229 individuals participated in the baseline interviews and 201 completed both baseline and endpoint interviews, corresponding to a dropout rate of $12 \%$. The main reasons for dropout included being no longer employed at the worksite or being unable to reach; $<3 \%$ refused to complete the endpoint interview. Food diaries were completed by $90 \%$ of the subjects interviewed at baseline and by $84 \%$ of the subjects interviewed at endpoint ( $n$ 168).

\section{Canteen survey}

Data on the canteen nutrition environment (worksites with in-house canteens) were collected by aggregating individual-level lunch intake data at baseline and at endpoint. A duplicate plate method was used with subsequent chemical analysis to quantify actual lunch intakes. The procedure was the same as that used in a previous study $^{(17)}$. Duplicate plates were collected at baseline and at endpoint from a total of twelve customers at each canteen on two different days (six samples per day). The employees waiting in line for lunch were randomly asked whether they would participate in the study. No more than two persons at each canteen refused to participate. The laboratory technicians then observed and collected identical dishes of the employees' chosen food items. The employees were asked to return the plates to the technicians in order to record plate waste. They were also asked to fill out a short questionnaire that included questions on gender, age, weight, height and occupational status.

The food items on each dish, excluding plate waste, were weighed separately. The recipes and cooking methods for the relevant dishes were provided by the canteen staff, thereby providing the basis for the calculation of the fruit and vegetable content of each dish. Beverages were not included in the analysis. The portions were individually mixed and homogenized. Analyses of the content of protein, fat and ash were performed according to procedures given by the Nordic Committee on Food Analysis. Dry matter content was determined by drying in a vacuum oven at $70^{\circ} \mathrm{C}$ to constant weight. Carbohydrate and energy content was calculated from contents of dry matter, protein, fat and $a s h^{(17)}$.

\section{Data analysis}

Data regarding the employee dietary survey presented in the tables in the current paper are limited to subjects who completed both the baseline and endpoint food diary registrations. The average food and nutrient intakes were calculated for each individual using the software GIES version 0995a (released 26 June 2005; Danish Food Institute, Technical University of Denmark, Soeborg, Denmark) and the Danish Food Composition Databank 
version 5 (October 2002; Soeborg, Denmark; www. Foodcomp.dk). BMI was calculated from self-reported height and weight data. For the assessment of underreporting of energy intake (EI), the EI:BMR ratio was determined for each individual. BMR was estimated using Schofield equations ${ }^{(18)}$.

Nutrient-related dependent variables in the employee dietary survey included content of energy, EI:BMR ratio, macronutrients (carbohydrate, protein and fat), sugar and fibre, whereas food-related dependent variables included fruit, vegetables, juice, potatoes and the food group 'cake and sweets'. Values were analysed in both absolute and relative forms (e.g. average $\mathrm{g} / \mathrm{d}$ and $\mathrm{g} / 10 \mathrm{MJ}$ or $\% \mathrm{E}$ ). Fruit and vegetables were classified according to Danish guidelines for the recommended intake of fruit and vegetables ( $\geq 600 \mathrm{~g} / \mathrm{d}$, excluding potatoes and including not more than $100 \mathrm{ml}$ fruit juice/ $\left.\mathrm{d}^{(19)}\right)$. The group 'cake and sweets' included ice cream, all kinds of cakes, chocolate, sweets and chips. With regard to the canteen survey, the following dietary variables were included: energy, fat (\%E) and vegetables and fruit (g/meal). Dishes were categorized into three food choice groups: hot meals; sandwiches (mainly open sandwiches); and salad only or mixed meals (hot meals/sandwiches together with salad, fruit or snack vegetables).

Data were statistically analysed using the software program SAS Enterprise Guide and a $P$ value of 0.05 was chosen as the significance level. Intake data from both the employee dietary survey and the canteen survey were modelled by a multidimensional variance model and analysed using PROC GLM with the multidimensional variance analysis (MANOVA) option. Tests are carried out of the 'overall' effect in the multidimensional model and later of the unidimensional effects. The variables in the employee dietary survey were: 'Intervention', 'Workplace (Intervention)', 'Age', 'BMI' and 'Gender', plus their twoway interactions. When 'Intervention' showed significant results, the analysis was split up by 'Intervention' in order to observe the changes in relation to zero changes. The variables in the canteen survey were the same as those in the employee dietary survey, with the added inclusion of 'Time' and 'Food choice'. The variable 'Time' was only relevant in the model for the data from the canteen survey, as different subjects participated at baseline and at endpoint, whereas data from the employee dietary survey were conducted on differences between endpoint and baseline in order to account for the paired data structure. When testing the overall significance of variables in the MANOVA, the heavily correlated response variables were taken out of the analysis, such as values calculated both as average $\mathrm{g} / \mathrm{d}$ and $\mathrm{g} / 10 \mathrm{MJ}$.

The transformation of data was carried out for all response variables whose residuals from a full model did not meet a satisfying level of normality. The transformation was conducted by applying a Box-Cox transformation. For data on differences (employee dietary survey), a modified Box-Cox transformation was used, adding the constant $\mathrm{K}$, since we wished to test whether the changes from endpoint values to baseline were significant. Thus, the Box-Cox transformed values were adjusted back (by adding $\mathrm{K}$ ) so that a zero in the transformed values corresponded to a zero in the original values. Only the response variable Juice could not be transformed into a continuous normal distribution. Differences in juice intake were later divided into three categories, $<0,0$ and $>0$ of the differences, and analysed separately using the proportional odds model. The principles in the proportional odds model are described elsewhere ${ }^{(15)}$.

\section{Results}

\section{Subject characteristics}

Baseline characteristics of the subjects participating in the employee dietary survey and the canteen survey are presented in Table 2. A majority of the subjects participating in

Table 2 Baseline characteristics of subjects participating in the employee dietary survey and baseline and endpoint characteristics of subjects participating in the canteen survey (intervention and minimum intervention control group, respectively)

\begin{tabular}{|c|c|c|c|c|c|c|c|c|c|c|}
\hline & \multirow{2}{*}{$\begin{array}{c}\begin{array}{c}\text { Gender } \\
\text { (male) }\end{array} \\
\%\end{array}$} & \multicolumn{2}{|c|}{$\begin{array}{c}\text { Age } \\
\text { (years) }\end{array}$} & \multicolumn{2}{|c|}{$\begin{array}{l}\text { Weight } \\
(\mathrm{kg})\end{array}$} & \multicolumn{2}{|c|}{$\begin{array}{l}\text { Height } \\
(\mathrm{cm})\end{array}$} & \multicolumn{2}{|c|}{$\begin{array}{c}\mathrm{BMI} \\
\left(\mathrm{kg} / \mathrm{m}^{2}\right)\end{array}$} & \multirow{2}{*}{$\begin{array}{c}\begin{array}{c}\text { Members of } \\
\text { workers' union }\end{array} \\
\% \%\end{array}$} \\
\hline & & Mean & SD & Mean & SD & Mean & $\mathrm{SD}$ & Mean & SD & \\
\hline \multicolumn{11}{|l|}{ Employee dietary survey* } \\
\hline Intervention group ( $n$ 102) & 55 & 44 & 9 & 79 & 19 & 175 & 10 & $25 \cdot 5$ & $4 \cdot 3$ & 89 \\
\hline Minimum intervention control group ( $n$ 66) & 64 & 41 & 10 & 80 & 17 & 175 & 10 & $25 \cdot 9$ & $4 \cdot 1$ & 74 \\
\hline \multicolumn{11}{|l|}{ Canteen surveyt } \\
\hline \multicolumn{11}{|l|}{ Baseline } \\
\hline Intervention group ( $n$ 48) & 65 & 40 & 8 & 79 & 17 & 176 & 11 & $25 \cdot 7$ & $4 \cdot 6$ & $\mathrm{~N} / \mathrm{A}$ \\
\hline Minimum intervention control group ( $n$ 24) & 54 & 43 & 10 & 80 & 13 & 175 & 9 & $26 \cdot 1$ & $3 \cdot 7$ & $\mathrm{~N} / \mathrm{A}$ \\
\hline \multicolumn{11}{|l|}{ Endpoint } \\
\hline Intervention group ( $n$ 48) & 60 & 41 & 11 & 79 & 14 & 177 & 9 & $25 \cdot 3$ & $3 \cdot 7$ & $\mathrm{~N} / \mathrm{A}$ \\
\hline Minimum intervention control group ( $n$ 24) & 54 & 43 & 8 & 77 & 16 & 176 & 8 & $24 \cdot 9$ & $3 \cdot 7$ & $\mathrm{~N} / \mathrm{A}$ \\
\hline
\end{tabular}

N/A, not available.

*Same subjects participated at baseline and at endpoint.

tDifferent subjects participated at baseline and at endpoint. 
the employee dietary survey were members of the General Workers' Union organizing unskilled workers, and slightly more men compared with women participated in the survey. Average BMI was 25.5 and $25.9 \mathrm{~kg} / \mathrm{m}^{2}$ in the intervention and minimum intervention control groups, respectively. With regard to the characteristics of subjects participating in the canteen survey at baseline and at endpoint the same features were observed, with average BMI ranging from $25 \cdot 3$ to $26 \cdot 1 \mathrm{~kg} / \mathrm{m}^{2}$ and male participants being slightly overweight (Table 2 ). We have no information on the subjects' union membership.

\section{Employee dietary survey}

Baseline values are shown in Table 3. In all, $23 \%$ of participants had an EI:BMR ratio below the Goldberg cutoff value of 1.06 (not shown). The data include these possible under-reporters, as removal of under-reporters did not change the overall results. The intervention and minimum intervention control groups were not significantly different from each other at baseline in relation to either food $(P=0 \cdot 88)$ or nutrient response $(P=0 \cdot 41)$.

Table 4 shows changes in intervention and minimum intervention control groups from baseline to endpoint in intakes of energy, nutrients and foods. There were no significant effects of 'Gender', 'BMI' or 'Age' on changes. In the intervention group, overall significant changes in intakes were found from baseline to endpoint for both food $(P=0 \cdot 002)$ and nutrient responses $(P<0 \cdot 001)$. More specifically, significant decreases were found in the intervention group with regard to the relative and absolute intake of total fat, as well as with regard to the absolute intakes of saturated fat and 'cake and sweets' $(\mathrm{g} /$ day and $\mathrm{g} / 10 \mathrm{MJ})$. Moreover, a median increase in intake of dietary fibre per $10 \mathrm{MJ}$ was seen in the intervention group. All these changes were significantly different from changes seen in the minimum intervention control group. In addition, a significant median increase in intake of fruit and vegetables was seen when expressed per $10 \mathrm{MJ}$, as well as a significant increase in fruit intake (g/day and $\mathrm{g} / 10 \mathrm{MJ})$, in the intervention group. However, these changes were not significantly different from those seen in the minimum intervention group.

The minimum intervention control group revealed no overall significant changes in food intakes $(P=0 \cdot 45)$, but showed significant changes in overall nutrient intakes $(P=0.042)$ from baseline to endpoint. The response variables in the minimum intervention group with changes being significantly different from zero were the relative contents of fat and carbohydrate as well as the relative and absolute intakes of added sugar. In all these cases, except for added sugar, the changes in the intervention group were significantly different from those seen in the minimum

Table 3 Baseline intakes of energy, nutrients and foods in the intervention and minimum intervention control groups, respectively (employee dietary survey)

\begin{tabular}{|c|c|c|c|c|c|c|}
\hline & \multicolumn{3}{|c|}{ Intervention group ( $n$ 102) } & \multicolumn{3}{|c|}{ Minimum intervention control group ( $n 66)$} \\
\hline & Median & 25th percentile & 75th percentile & Median & 25th percentile & 75th percentile \\
\hline Energy $(\mathrm{kJ})$ & 9114 & 7182 & 11034 & 8994 & 7473 & 11806 \\
\hline El:BMR & $1 \cdot 3$ & $1 \cdot 1$ & 1.5 & $1 \cdot 3$ & $1 \cdot 1$ & $1 \cdot 7$ \\
\hline \multicolumn{7}{|l|}{ Nutrients } \\
\hline Fat $(\% \mathrm{E})$ & 34 & 30 & 38 & $32 \cdot 6$ & $29 \cdot 5$ & $36 \cdot 4$ \\
\hline Fat (\%E) (excluding alcohol) & 35 & 31 & 40 & 34 & 30 & 39 \\
\hline Fat $(g / d)$ & 79 & 60 & 99 & 74 & 59 & 104 \\
\hline Saturated fat $(\mathrm{g} / \mathrm{d})$ & 33 & 25 & 42 & 30 & 24 & 42 \\
\hline Carbohydrate (\%E) & 49 & 44 & 53 & 50 & 44 & 55 \\
\hline Protein (\%E) & 13 & 12 & 15 & 13 & 12 & 15 \\
\hline Added sugar ( $\mathrm{g} / \mathrm{d}$ ) & 43 & 24 & 70 & 45 & 19 & 69 \\
\hline Added sugar (g/10 MJ) & 47 & 29 & 70 & 45 & 23 & 64 \\
\hline Fibre $(g / d)$ & 20 & 14 & 24 & 22 & 17 & 25 \\
\hline Fibre $(\mathrm{g} / 10 \mathrm{MJ})$ & 21 & 17 & 27 & 23 & 19 & 27 \\
\hline \multicolumn{7}{|l|}{ Foods } \\
\hline Fruit and vegetables $(\mathrm{g} / \mathrm{d})^{\star} \dagger$ & 282 & 181 & 436 & 343 & 210 & 557 \\
\hline Vegetables $(\mathrm{g} / \mathrm{d})^{\star}$ & 131 & 77 & 192 & 138 & 99 & 209 \\
\hline Fruit $(g / d)$ & 116 & 29 & 223 & 163 & 68 & 276 \\
\hline Juice $(g / d)$ & 0 & 0 & 90 & 0 & 0 & 90 \\
\hline Fruit and vegetables $(\mathrm{g} / 10 \mathrm{MJ})^{*}+$ & 313 & 182 & 466 & 380 & 196 & 614 \\
\hline Vegetables $(\mathrm{g} / 10 \mathrm{MJ})^{*}$ & 136 & 78 & 205 & 152 & 103 & 243 \\
\hline $\begin{array}{l}\text { Fruit }(g / 10 M J) \\
\text { Juice }(g / 10 M J)\end{array}$ & 118 & 28 & 230 & 152 & 53 & 289 \\
\hline Potatoes $(\mathrm{g} / \mathrm{d})$ & 86 & 50 & 130 & 79 & 24 & 136 \\
\hline Potatoes ( $\mathrm{g} / 10 \mathrm{MJ})$ & 101 & 50 & 143 & 76 & 30 & 138 \\
\hline Cake and sweets $(g / d) \ddagger$ & 53 & 25 & 99 & 51 & 18 & 114 \\
\hline Cake and sweets $(\mathrm{g} / 10 \mathrm{MJ}) \ddagger$ & 67 & 32 & 94 & 60 & 17 & 108 \\
\hline
\end{tabular}

El, energy intake.

${ }^{*}$ Excluding potatoes.

tIncluding not more than $100 \mathrm{~g}$ fruit juice per person per day.

flncluding ice cream, all kinds of cakes, chocolate, sweets and chips. 
Table 4 Changes in intervention and minimum intervention control groups from baseline to endpoint in intakes of energy, nutrients and foods (employee dietary survey)

\begin{tabular}{|c|c|c|c|c|c|c|c|}
\hline & \multicolumn{3}{|c|}{$\begin{array}{l}\text { Intervention group } \\
(n \text { 102) }\end{array}$} & \multicolumn{3}{|c|}{$\begin{array}{l}\text { Minimum intervention control group } \\
\qquad(n 66)\end{array}$} & \multirow{2}{*}{$\begin{array}{c}\begin{array}{c}\text { Intervention } v . \\
\text { minimum intervention } \\
\text { control group }\end{array} \\
P \text { value }\end{array}$} \\
\hline & Median change* & $95 \% \mathrm{Cl}$ & $P$ value & Median change* & $95 \% \mathrm{Cl}$ & $P$ value & \\
\hline $\begin{array}{l}\text { Energy (kJ) } \\
\text { El:BMR }\end{array}$ & $\begin{array}{l}-869 \\
-0 \cdot 12\end{array}$ & $\begin{array}{l}-1397,-342 \\
-0 \cdot 19,-0 \cdot 05\end{array}$ & $\begin{array}{l}0.003 \\
0.002\end{array}$ & $\begin{array}{l}-266 \\
-0.04\end{array}$ & $\begin{array}{l}-872,339 \\
-0 \cdot 13,0.05\end{array}$ & $\begin{array}{l}0.44 \\
0 \cdot 40\end{array}$ & $\begin{array}{l}0 \cdot 16 \\
0 \cdot 17\end{array}$ \\
\hline \multicolumn{8}{|l|}{ Nutrients } \\
\hline Fat $(\% \mathrm{E})$ & $-2 \cdot 2$ & $-3 \cdot 4,-1 \cdot 0$ & 0.002 & 1.5 & $0 \cdot 2,2 \cdot 7$ & 0.049 & $<0.001$ \\
\hline Fat (\%E) (excluding alcohol) & $-2 \cdot 1$ & $-3 \cdot 3,-0 \cdot 8$ & 0.006 & $1 \cdot 8$ & $0.5,3 \cdot 0$ & 0.022 & $<0.001$ \\
\hline Fat $(g / d)$ & -13 & $-19,-7$ & $<0.001$ & 0 & $-6,7$ & 0.99 & 0.007 \\
\hline Saturated fat $(\mathrm{g} / \mathrm{d})$ & -5 & $-8,-3$ & $<0.001$ & 0 & $-3,3$ & 0.74 & 0.028 \\
\hline Carbohydrate (\%E) & $1 \cdot 2$ & $-0 \cdot 2,2 \cdot 5$ & $0 \cdot 14$ & -1.9 & $-3 \cdot 5,-0 \cdot 4$ & 0.025 & 0.010 \\
\hline Protein $(\% \mathrm{E})$ & $0 \cdot \overline{7}$ & $0 \cdot 2,1 \cdot 1$ & 0.022 & $-0 \cdot 2$ & $-0 \cdot 8,0 \cdot 4$ & 0.60 & 0.07 \\
\hline Added sugar (g/d) & -8 & $-15,-1$ & 0.019 & -7 & $-14,-1$ & 0.049 & 0.78 \\
\hline Added sugar (g/10 MJ) & -8 & $-12,-2$ & 0.002 & -6 & $-12,-1$ & 0.039 & 0.68 \\
\hline Fibre $(\mathrm{g} / \mathrm{d})$ & 1 & $-1,-4$ & 0.27 & 0 & $-2,1$ & 0.96 & 0.44 \\
\hline Fibre (g/10 MJ) & 3 & 2,5 & $<0.001$ & 0 & $-1,2$ & 0.49 & 0.035 \\
\hline \multicolumn{8}{|l|}{ Foods } \\
\hline Fruit and vegetables $(\mathrm{g} / \mathrm{d})+\ddagger$ & 44 & $-4,93$ & 0.07 & 16 & $-37,71$ & 0.48 & 0.41 \\
\hline Vegetables $(\mathrm{g} / \mathrm{d}) \dagger$ & 11 & $-11,32$ & $0 \cdot 33$ & 20 & $-9,47$ & $0 \cdot 15$ & $0 \cdot 10$ \\
\hline Fruit $(\mathrm{g} / \mathrm{d})$ & 55 & 16,94 & 0.007 & 13 & $-48,74$ & 0.41 & 0.85 \\
\hline Fruit and vegetables $(\mathrm{g} / 10 \mathrm{MJ})+\ddagger$ & 95 & 36,154 & 0.002 & 36 & $-25,97$ & 0.22 & 0.25 \\
\hline Vegetables $(\mathrm{g} / 10 \mathrm{MJ}) \dagger$ & 25 & 0,48 & 0.05 & 30 & $-4,62$ & 0.08 & 0.35 \\
\hline Fruit $(\mathrm{g} / 10 \mathrm{MJ})$ & 74 & 20,128 & 0.009 & 14 & $-32,60$ & 0.51 & 0.09 \\
\hline Potatoes $(\mathrm{g} / \mathrm{d})$ & 14 & 2,37 & 0.030 & -10 & $-34,13$ & 0.44 & $0 \cdot 15$ \\
\hline Potatoes $(\mathrm{g} / 10 \mathrm{MJ})$ & 30 & 9,50 & 0.005 & -15 & $-44,14$ & 0.33 & 0.06 \\
\hline Cake and sweets $(\mathrm{g} / \mathrm{d}) \S$ & -19 & $-30,-7$ & 0.002 & 2 & $-14,17$ & 0.82 & 0.037 \\
\hline Cake and sweets $(\mathrm{g} / 10 \mathrm{MJ}) \S$ & -18 & $-29,-7$ & 0.002 & 3 & $-11,17$ & 0.65 & 0.032 \\
\hline
\end{tabular}

Significant differences are highlighted in bold $(P \leq 0 \cdot 05)$.

*Endpoint - baseline.

tExcluding potatoes.
flncluding not more than $100 \mathrm{~g}$ fruit juice per person per day.

flncluding not more than $100 \mathrm{~g}$ fruit juice per person per day.
SIncluding ice cream, all kinds of cakes, chocolate, sweets and chips. 
Table 5 Significant variables and median differences in energy intake, fat energy intake and content of fruit and vegetables in the intervention and minimum intervention control groups (canteen survey, $n$ 144)

\begin{tabular}{lrl}
\hline Significant variables & $\begin{array}{c}\text { Median } \\
\text { difference }\end{array}$ & $P$ value \\
\hline Energy (MJ/meal) & & \\
$\quad$ Male - female & 0.7 & $<0.001$ \\
Fat (\%E) & & \\
$\quad$ Baseline - endpoint in intervention group & -11 & $<0.001$ \\
$\quad$ Sandwiches - hot meals & 12 & $<0.001$ \\
$\quad$ Sandwiches - salad/mixed meals & 8 & $<0.001$ \\
Fruit and vegetables (g/meal) & & \\
$\quad$ Sandwiches - hot meals & -44 & $<0.001$ \\
$\quad$ Sandwiches - salad/mixed meals & -150 & $<0.001$ \\
\hline
\end{tabular}

*Excluding potatoes.

intervention group, with the most nutritionally favourable changes observed in the intervention group (Table 4).

Juice intake $(\mathrm{g} / \mathrm{d})$ did not change significantly from baseline to endpoint, either in the intervention group or in the minimum intervention control group $(P=0.72$ and $0 \cdot 53$, respectively, data not shown).

\section{Canteen survey}

Table 5 shows significant variables and medium differences with respect to the canteen lunch content of energy, fat and fruit and vegetables. Overall, no effect from baseline to endpoint was seen in the minimum intervention control group for any of the nutrients ( $P=0.89$ for 'Time', not shown), whereas in the intervention group the variable fat content $(\% \mathrm{E})$ differed significantly from baseline to endpoint (median reduction being $11 \% \mathrm{E}$ from baseline to endpoint (Table 5), $P<0 \cdot 001$ ).

A 'Gender' effect was seen with respect to energy intake. The median difference between genders was $0.7 \mathrm{MJ}$ (Table 5; 2.6 and 1.9 MJ for male and female participants, respectively, data not shown). In addition, a 'Food choice' effect was seen with respect to the relative fat content as well as fruit and vegetable content. Sandwich meals had the least favourable nutrient profile, e.g. more fat and less fruit and vegetables, compared with the other two meal groups (Table 5). The estimated median content of fat for the intervention group at baseline was 49, 36 and $41 \% \mathrm{E}$, and 25, 30 and $38 \% \mathrm{E}$ at endpoint for sandwiches, hot meals and salad/mixed meals, respectively (not shown). Regarding fruit and vegetable content, the median estimated content was 37, 81 and $187 \mathrm{~g}$ for sandwiches, hot meals and salad/mixed meals, respectively, with no difference observed between baseline and endpoint (data not shown).

\section{Discussion}

The present participatory 'Food at Work' study, guided by an ecological framework targeting both individual and environment levels, showed significant improvements in food habits among employees. The present study was carried out in blue-collar worksites and is characterized by the active involvement of the union as well as by a high extent of self-determination by the worksites to implement nutrition-related activities.

From a nutritional point of view, several significant positive effects among employees were observed in the intervention group, including a significant median decrease of $2 \cdot 2 \% \mathrm{E}$ obtained from fat and a median increase of $3 \mathrm{~g} / 10 \mathrm{MJ}$ in fibre intake. These changes were all significantly different from those seen in the minimum intervention control group. Moreover, participants in the intervention group significantly increased daily fruit and vegetable intake by $95 \mathrm{~g} / 10 \mathrm{MJ}$. The intervention effect appeared to be greater for fruit $(55 \mathrm{~g} / \mathrm{d}$ and $74 \mathrm{~g} / 10 \mathrm{MJ})$ than for vegetables, which is consistent with results obtained in other community-based dietary intervention studies ${ }^{(20,21)}$

The results of total fruit and vegetable increase in the present study seem to be comparable to the impact observed in large multi-component worksite trials, conducted predominantly in the USA ${ }^{(22,23)}$. Thorogood et $a{ }^{(9)}$ summarized eight randomized controlled worksite trials in a meta-analysis, and showed an increase in consumption of close to $0 \cdot 2$ servings of fruit and vegetables/d. Buttriss et al. ${ }^{(22)}$ drew special attention to one of these studies, the Treatwell 5-a-Day Study, showing that involving family members could be a promising strategy to increase fruit and vegetable intake ${ }^{(24)}$, with potential benefits for the whole family ${ }^{(25)}$. Tailored health information and different counselling opportunities were provided in two more recently published intervention studies, one among construction labourers using telephone-delivered and mailed intervention ${ }^{(26)}$ and another targeting firefighters either through a team-centred curriculum or through individual motivational interviews ${ }^{(27)}$. In these cases, intervention effects of approximately 1-1.5 servings of fruit and vegetables were observed, comparable to the effect found in a study targeting solely the physical environment, making fruit and vegetables in lunch meals easily available and more appealing at worksite canteens ${ }^{(28,29)}$. In terms of reduction of fat intake, two of the largest worksite intervention evaluations, the Working Well Trial ${ }^{(30)}$ and the Next Stop Trial ${ }^{(31)}$, reported a net reduction of $0 \cdot 4 \% \mathrm{E}$ and $1 \% \mathrm{E}$, respectively ${ }^{(9)}$, obtained from fat.

In the present study, a favourable change in the canteen nutrition environment was shown, indicating a median fat reduction of $11 \% \mathrm{E}$ of the lunch selected by employees in the intervention group. There was no change in either energy intake or fruit and vegetable content during the intervention in the canteen nutrition environment. The canteen managers decided themselves to focus more on reducing the fat content in meals rather than on increasing the content of fruit and vegetables. 
The canteen survey found a median lunch energy content of $2 \cdot 7$ and $2 \cdot 0 \mathrm{MJ}$ for meals consumed by men and women, respectively, not including beverages, which is comparable to results from a former published canteen survey $^{(17)}$. The nutritional profile of the meals seemed to be dependent largely on food choice. Thorsen et al. ${ }^{(32)}$ found that only one out of eight of the canteens participating in a self-administered questionnaire survey fulfilled the combined defined health criteria for open sandwiches, hot meals and salad meal options. This emphasizes the importance of developing strategies to improve the nutritional content in all meal types, making the healthier choices both more appealing and accessible for customers with different food choice preferences. It is, however, well recognized that improving the nutritional quality of food served by food services can be challenging, and efforts to change the food selection and content may be met with resistance by both canteen staff and customers $^{(33-35)}$. In order to support the ongoing progress towards healthier menu meals, the provision of an assessment tool directed at worksite canteens would be valuable for conducting self-evaluation and setting targets for work ${ }^{(36)}$.

The present study has several limitations, including small sample sizes as well as differences in background variables between groups, as worksites rather than individuals were randomized in the study. Moreover, the findings of the employee dietary survey are based on self-reported information. A $4 \mathrm{~d}$ estimated dietary record is usually considered a valid and reliable method for measuring current dietary habits, but a $7 \mathrm{~d}$ food record is preferable $^{(16)}$. The use of standard recipes for many dishes and standard portions for the amount of fat used for frying may have underestimated the real differences and thereby diminished the actual intervention effect. Another limitation may be the brief duration of the intervention period, which may influence the size of the effect $^{(22)}$. Moreover, no follow-up was conducted to assess the sustainability of the intervention effect. It has been reasoned, however, that an intervention based on participatory approach and tailored to the unique characteristics of each site and with a high degree of local project ownership may increase the likelihood of becoming institutionalized into the usual routine of practice $^{(37,38)}$. A strength of the present study is that a process evaluation was performed given information on employees' and key actors' involvement and perception of the intervention ${ }^{(15)}$. A positive attitude was seen towards the worksite promoting and implementing healthy eating, and this may have been the reason for the positive outcome results on food intake in the intervention group.

The median EI:BMR value at endpoint was significantly lower compared with that at baseline in the intervention group. However, no significant differences between the intervention and minimum intervention control groups were seen with regard to the changes in EI:BMR. Difference in low energy intake reports between intervention and control groups could distort results from dietary intervention trials; therefore, interpretation of findings from dietary trials must include this potential bias ${ }^{(39)}$. In order to avoid possible bias caused by different intakes of energy by nutrients, the amount of food consumed was adjusted for energy intake (expressed per 10 MJ). Nevertheless, it cannot be excluded that a reporting bias has been introduced when reporting intake per $10 \mathrm{MJ}$, as participants may under-report intake of some foods and not that of more socially desirable foods, such as fruit and vegetables. The size of such systematic errors cannot be estimated, but it is unlikely that it accounts for all the improvements in diet found in the present study. Furthermore, the results of the food diaries are supported by the canteen survey showing a similar positive trend.

In conclusion, the positive findings of the present study are of particular interest considering the scarcity of especially European studies addressing healthy eating in blue-collar worksites. Further, the present study shows that worksite canteens may make a significant difference in reducing the percentage of energy from fat. From a public view, even small changes in food intake and physical activity, maintained over a longer period of time, could have a large impact on public health. The results of the present study are promising; however, the number of participating worksites is too limited for broader generalizations. More research is required on innovative prevention strategies addressing both the psychical environment at the worksite and how social support can be strengthening, both between co-workers and by involving the whole family to optimize adherence. In addition, tools and resources to support employer efforts in health promotion should be developed and evaluated. Over time, this type of dietary change programme has the potential for considerable access into communities, thereby contributing significantly to the larger public health goal of reducing incidences of diet-related diseases.

\section{Acknowledgements}

The present study was funded by the Danish Ministry of Family and Consumer Affairs and by the General Workers' Union in Denmark. The authors have no conflict of interest to declare. H.M.S. contributed to the statistical analysis of the data. All authors contributed to the study concept and design, as well as to interpretation of data and preparation of the manuscript. Valuable statistical inputs were provided by Jens Strodl Andersen, formerly employed at National Food Institute, Technical University of Denmark. Eva Stanley Hörning and Julie WedellWedellsborg wrote their Masters thesis at the Faculty of Life Sciences, University of Copenhagen, on the basis of 
the material contained in the present study. The authors thank Kirsten Skovmand Hansen and the laboratory staff for collecting samples at the worksite canteens and for performing the laboratory analyses, and Hanne-Jette Hinsch and Tue Christensen from the National Food Institute for their guidance and support. The authors also thank all those who took part in the project, including the staff and managers at the eight worksites and the project team members.

\section{References}

1. Ball K \& Crawford D (2009) Socioeconomic status and weight change in adults: a review. Soc Sci Med 60, 1987-2010

2. Groth MV, Fagt S, Stockmarr A et al. (2009) Dimensions of socioeconomic position related to body mass index and obesity among Danish women and men. Scand J Public Health 37, 418-426.

3. Lallukka T, Laaksonen M, Rahkonen O et al. (2007) Multiple socio-economic circumstances and healthy food habits. Eur J Clin Nutr 61, 701-710.

4. World Health Organization (2006) European Charter on Counteracting Obesity. Copenhagen: WHO Regional Office for Europe.

5. Wrieden WL, Connaghan J, Morrison C et al. (2004) Secular and socio-economic trends in compliance with dietary targets in the north Glasgow MONICA population surveys 1986-1995: did social gradients widen? Public Health Nutr 7, 835-842

6. European Commission (2005) Green Paper - Promoting Healthy Diets and Physical Activity: A European Dimension for the Prevention of Overweight, Obesity and Chronic Diseases. COM/2005/0637. Brussels: EC.

7. Pomerleau J, Lock K, Knai C et al. (2005) Interventions designed to increase adult fruit and vegetable intake can be effective: a systematic review of the literature. J Nutr $\mathbf{1 3 5}$, 2486-2495.

8. Stockley L (2001) Toward public health nutrition strategies in the European Union to implement food based dietary guidelines and to enhance healthier lifestyles. Public Health Nutr 4, 307-324.

9. Thorogood M, Simera I, Dowler E et al. (2007) A systematic review of population and community dietary interventions to prevent cancer. Nutr Rev 20, 74-88.

10. Glasgow RE, McCaul KD \& Fisher KJ (1993) Participation in worksite health promotion: a critique of the literature and recommendations for future practice. Health Educ $Q \mathbf{2 0}$, 391-408.

11. Engbers LH, van Poppel MN, Chin AP et al. (2006) The effects of a controlled worksite environmental intervention on determinants of dietary behavior and self-reported fruit, vegetable and fat intake. BMC Public Health 6, 253.

12. Baranowski T, Cullen KW, Nicklas T et al. (2003) Are current health behavioral change models helpful in guiding prevention of weight gain efforts? Obes Res 11, Suppl., 23S-43S.

13. Dorfman L \& Wallack L (2007) Moving nutrition upstream: the case for reframing obesity. J Nutr Educ Behav 39, S45-S50.

14. Institute of Preventive Medicine Environmental and Occupational Health - PROLEPSIS (2008) Report on the Evaluation of Policies and Best Practices Targeting Obesity at the Workplace. Guidelines for the Prevention of Obesity at the Workplace. http://gpow.eu/media/file/policies $\% 20$ and $\% 20$ best $\% 20$ practices $\% 28$ without $\% 20$ articles $\% 29 \% 20$ $\% 282 \% 29 . p d f /$
15. Lassen A, Bruselius-Jensen M, Sommer HM et al. (2007) Factors influencing participation rates and employees' attitudes toward promoting healthy eating at blue-collar worksites. Health Educ Res 22, 727-736.

16. Biltoft-Jensen A, Matthiessen J, Rasmussen LB et al. (2009) Validation of the Danish 7-day pre-coded food diary among adults: energy intake $v$. energy expenditure and recording length. Br J Nutr 102, 1838-1846.

17. Lassen A, Hansen K \& Trolle E (2007) Comparison of buffet and à la carte serving at worksite canteens on nutrient intake and fruit and vegetable consumption. Public Health Nutr 10, 292-297.

18. Food and Agriculture Organization/World Health Organization/United Nations University (2004) Human Energy Requirements: Report of a Joint FAO/WHO/UNU Expert Consultation Food and Agriculture Organization. Rome: FAO.

19. Astrup A, Andersen NL, Stender S et al. (2005) Kostrådene 2005 (Dietary Guidelines 2005). Copenhagen: Danish Institute for Food and Veterinary Research \& Danish Nutritional Council.

20. Campbell MK, Tessaro I, DeVellis B et al. (2002) Effects of a tailored health promotion program for female blue-collar workers: health works for women. Prev Med 34, 313-323.

21. Resnicow K, Campbell MK, Carr C et al. (2004) Body and soul. A dietary intervention conducted through AfricanAmerican churches. Am J Prev Med 27, 97-105.

22. Buttriss J, Stanner S, McKevith AP et al. (2004) Successful ways to modify food choice: lessons from the literature. Nutr Bull 29, 333-343.

23. Story M, Kaphingst KM, Robinson-O'Brien R et al. (2008) Creating healthy food and eating environments: policy and environmental approaches. Annu Rev Public Health 29, 253-272.

24. Sorensen G, Stoddard A, Peterson K et al. (1999) Increasing fruit and vegetable consumption through worksites and families in the treatwell 5-a-day study. Am J Clin Nutr 89, 54-60.

25. Brekke HK, Sunesson A, Axelsen M et al. (2004) Attitudes and barriers to dietary advice aimed at reducing risk of type 2 diabetes in first-degree relatives of patients with type 2 diabetes. J Hum Nutr Diet 17, 513-521.

26. Sorensen G, Barbeau EM, Stoddard AM et al. (2007) Tools for health: the efficacy of a tailored intervention targeted for construction laborers. Cancer Causes Control 18, 51-59.

27. Elliot DL, Goldberg L, Kuehl KS et al. (2007) The PHLAME (Promoting Healthy Lifestyles: Alternative Models' Effects) firefighter study: outcomes of two models of behavior change. J Am Diet Assoc 49, 204-213.

28. Lassen A, Thorsen AV, Trolle E et al. (2004) Successful strategies to increase the consumption of fruits and vegetables: results from the Danish ' 6 a day' Work-site Canteen Model Study. Public Health Nutr 7, 263-270.

29. Thorsen AV, Lassen AD, Tetens I et al. (2010) Longterm sustainability of a worksite canteen intervention of serving more fruit and vegetables. Public Health Nutr 13, $1647-1652$.

30. Sorensen G, Thompson B, Glanz K et al. (1996) Work sitebased cancer prevention: primary results from the Working Well Trial. Am J Clin Nutr 86, 939-947.

31. Tilley BC, Glanz K, Kristal AR et al. (1999) Nutrition intervention for high-risk auto workers: results of the Next Step Trial. Prev Med 28, 284-292.

32. Thorsen AV, Lassen AD, Andersen JS et al. (2009) Workforce gender, company size and corporate financial support are predictors of availability of healthy meals in Danish worksite canteens. Public Health Nutr 12, 2068-2073.

33. Glanz K, Resnicow K, Seymour J et al. (2007) How major restaurant chains plan their menus: the role of profit, demand, and health. Am J Prev Med 32, 383-388. 
34. Pope R \& Cooney M (2005) The Heartbeat Award for caterers: experiences of health professionals involved. Health Educ J 54, 322-333.

35. Steenhuis I, Van AP, Reubsaet A et al. (2004) Process evaluation of two environmental nutrition programmes and an educational nutrition programme conducted at supermarkets and worksite cafeterias in the Netherlands. J Hum Nutr Diet 17, 107-115.

36. Lassen AD, Biltoft-Jensen A, Hansen GL et al. (2010) Development and validation of a new simple Healthy Meal Index for canteen meals. Public Health Nutr 13, 1559-1565.
37. O'Loughlin J, Renaud L, Richard L et al. (1998) Correlates of the sustainability of community-based heart health promotion interventions. Prev Med 27, 702-712.

38. Stange KC, Goodwin MA, Zyzanski SJ et al. (2003) Sustainability of a practice-individualized preventive service delivery intervention. Am J Prev Med 25, 296-300.

39. Caan B, Ballard-Barbash R, Slattery ML et al. (2004) Low energy reporting may increase in intervention participants enrolled in dietary intervention trials. J Am Diet Assoc 104, 357-366. 